\title{
Identification of a major surface protein on Neospora caninum tachyzoites
}

\begin{abstract}
Neospora caninum is a recently identified coccidian parasite that is closely related to Toxoplasma gondii. Molecules associated with the surface of N. caninum tachyzoites are likely to be involved in the process of adhesion and invasion of host cells. They probably also participate in the interaction of the parasite with the immune system, and they could play an important role in the pathogenesis of the parasite. To identify such surface molecules, we performed subcellular fractionation studies of isolated $N$. caninum tachyzoites. Employing the nonionic detergent Triton-X-114, we prepared a membrane fraction. Immunoblot analysis of this fraction using polyclonal antisera directed against tachyzoites of $N$. caninum and $T$. gondii resulted in the identification of a protein of approximately $43 \mathrm{kDa}(\mathrm{Nc}-\mathrm{p} 43)$. This molecule was present in two isolates of Neospora ( $\mathrm{Nc}-1$ and Liverpool) but was absent in Toxoplasma (RH-strain) tachyzoites. Further immunofluorescence and immunogold transmission electron microscopy (TEM) studies using affinity-purified anti-Nc-p43 antibodies demonstrated the presence of this molecule on the surface of $N$. caninum tachyzoites.
\end{abstract}

\section{Introduction}

Neospora caninum is an obligatory intracellular parasite that was originally identified in tissues of paralyzed dogs (Bjerkås and Presthus 1988; Dubey et al. 1988). In cattle, $N$. caninum is now regarded as a major cause of neonatal mortality and abortion in certain geographical areas (Barr et al. 1994). Other structurally and antigenically similar parasites have been reported from sheep, goats, and horses (Dubey and Lindsay 1993). The only two stages of the (largely unknown) life cycle of Neospora discovered to date are dividing tachyzoites and tissue cysts.

A. Hemphill ( $)$ B.Gottstein

Institute of Parasitology, University of Berne,

Laenggass-Strasse 122, CH-3012 Berne, Switzerland

fax: CH-31 6312622,e-mail: hemphill@ipa.unibe.ch
Prior to $1988, N$. caninum was misdiagnosed as Toxoplasma gondii due to its close structural similarity (Dubey 1992). However, due to distinct ultrastructural differences such as the thickness of the cyst wall and the number of rhoptries it had been possible to distinguish these two species from each other (Lindsay et al. 1993). Other criteria were found by immunohistochemistry using antisera directed against the corresponding parasites and by serological assays (Bjerkås and Presthus 1988; Bjerkås et al. 1994; Bjoerkman et al. 1994). Differences between Neospora and Toxoplasma were also demonstrated on the genetic level. Sequence analysis of nss-rRNA genes, the p22 and p30 gene loci (Brindley et al. 1993; Ellis et al. 1994; Holmdahl et al. 1994), the finding that the $T$. gondii-specific B1 gene is not present in $N$. caninum (Burg et al. 1989), and the sequence analysis and comparison of ribosomal DNA from bovine Neospora with that of similar coccidial parasites (Marsh et al. 1995) have suggested clear phylogenetic differences between Neospora spp. and T. gondii.

In vitro cultivation of tachyzoites has been achieved using several well-established cell lines (Lindsay and Dubey 1989; Dubey and Lindsay 1993). Infected bovine monocytes, bovine pulmonary artery endothelial cells, and cultured human foreskin fibroblast cells were used to compare the ultrastructural features of $N$. caninum and $T$. gondii (Lindsay et al. 1993). In vitro cultivation has also recently provided detailed information on the process of adhesion to and invasion of bovine aorta endothelial cells by $N$. caninum tachyzoites (Hemphill et al. 1996). Chemical and enzymatic modifications of both endothelial and parasite cell surfaces revealed that the initial contact between $N$. caninum and endothelial cells, as well as the invasion process itself, was a receptor-mediated event. The substantial nature of this receptor-ligand system was found to be based on protein-protein interactions rather than on protein-carbohydrate interactions (Hemphill et al. 1996). Thus, in analogy to T. gondii tachyzoites, parasite surface proteins of $N$. caninum play a crucial role during adhesion and penetration of the host cell membrane. 
Detailed studies on various aspects of host-parasite interactions have been carried out on $T$. gondii (Werk 1985; Bonhomme et al. 1992; Joiner and Dubremetz 1993; Kasper and Mineo 1994). The close relationship between $T$. gondii and $N$. caninum suggested that they would employ similar mechanisms and would use similar surface molecules to encounter their host cells. On the other hand, the distinct antigenic properties of these two species indicated a different surface-molecule composition (Dubey and Lindsay 1993). This is confirmed by the present report, which describes the identification of a novel protein in $N$. caninum tachyzoites with a molecular weight of $43 \mathrm{kDa}$ (named Nc-p43). We demonstrate that Nc-p43 is associated with the cell surface of $N$. caninum tachyzoites and that no immunologically related counterpart for this protein exists in $T$. gondii.

\section{Material and methods}

If not otherwise stated, all reagents and tissue-culture media were purchased from Sigma (St. Louis, Mo., USA).

\section{Vero-cell culture}

Cultures of Vero cells were maintained in $10-12 \mathrm{ml}$ of RPMI-1640 medium (Gibco) supplemented with 7\% fetal calf serum (FCS), $2 \mathrm{~m} M$ glutamine, $50 \mathrm{U}$ penicillin/ml, and $50 \mu \mathrm{g} /$ streptomycin $/ \mathrm{ml}$ at $37^{\circ} \mathrm{C} / 5 \% \mathrm{CO}_{2}$ in $\mathrm{T}-25$ tissue-culture flasks. Cultures were trypsinized at least once a week.

\section{Maintenance and purification of parasites}

Neospora caninum tachyzoites of the Nc-1 (Dubey et al. 1988) and Liverpool isolates (Barber et al. 1993) and Toxoplasma gondii tachyzoites of the RH strain (Sabin 1941) were maintained in Vero-cell monolayers at $37^{\circ} \mathrm{C} / 5 \% \mathrm{CO}_{2}$ in RPMI medium containing $2 \mathrm{~m} M$ glutamine, $50 \mathrm{U}$ penicillin $/ \mathrm{ml}, 50 \mu \mathrm{g}$ streptomycin $/ \mathrm{ml}$, and $7 \%$ FCS. Parasites were harvested from their feeder-cell cultures as previously described for $N$. caninum (Hemphill et al 1996). The preparation (containing tachyzoites and host cell debris) was washed twice in cold phosphate buffered saline (PBS). The final pellet was resuspended in $2 \mathrm{ml}$ of cold PBS and passed through a PD-10 column filled with Sephadex G25 M (Pharmacia) that had previously been equilibrated with PBS. The eluted, purified parasites were centrifuged at $4^{\circ} \mathrm{C}$ and resuspended in cold PBS. The viability of parasites was monitored by exclusion of trypan blue staining $(0.25 \%$ in PBS)

\section{Antisera}

Polyclonal rabbit anti- $N$. caninum (Nc-1-isolate; Hemphill et al 1996) and anti-T. gondii (RH-strain) antisera were used in this study. Prior to immunization of rabbits, samples of preimmune sera were taken so as to confirm the absence of antibodies directed against $T$. gondii and $N$. caninum tachyzoites by indirect immunofluorescence (Seefeldt et al. 1989; Trees et al. 1991). The serologically negative rabbits were inoculated intravenously with $10^{7}$ freshly purified tachyzoites. These procedures were repeated 2 times at intervals of 10 days before the sera were taken.
Subcellular fractionation of $N$. caninum tachyzoites employing Triton-X-114

$N$. caninum tachyzoites of the Nc-1-isolate $\left(5 \times 10^{7}-5 \times 10^{8} / \mathrm{ml}\right)$ were resuspended in $3 \mathrm{ml}$ of PBS, and phenylmethylsulfonyl fluoride (PMSF) was added to $0.2 \mathrm{mM}$. After $5 \mathrm{~min}$ of incubation on ice, the cell suspension was adjusted to $0.75 \%$ Triton-X114, and after gentle vortexing the parasites were extracted for $10 \mathrm{~min}$ on ice. The preparation was centrifuged $\left(30 \mathrm{~min} ; 10,000 \mathrm{~g} ; 4^{\circ} \mathrm{C}\right)$, and the supernatant was collected, whereas the pellet containing the (per definition) "cytoskeletal" preparation was discarded. The Triton-X-114 supernatant was then incubated at $30^{\circ} \mathrm{C}$ for $3 \mathrm{~min}$, cooled on ice for $10 \mathrm{~min}$, and centrifuged as described above to remove possible aggregates. The supernatant was collected and incubated at $30^{\circ} \mathrm{C}$ for $3 \mathrm{~min}$ again. The detergent and hydrophilic phases were separated by a further centrifugation step $(3 \mathrm{~min}$; $\left.1,000 \mathrm{~g} ; 24^{\circ} \mathrm{C}\right)$. The supernatant was removed, and the detergent phase was brought to $100 \mu \mathrm{l}$ with PBS. This final fraction, containing potential cell-surface membrane proteins, was then processed for sodium dodecyl sulfate-polyacrylamide gel electrophoresis (SDS-PAGE) by methanol/chloroform extraction as described elsewhere (Wessel and Fluegge 1984).

SDS-PAGE, immunoblotting, and chemical deglycosylation of nitrocellulose-bound proteins

Protein extracts of the various subcellular fractions (cell lysates of $N$. caninum Nc-1 and Liverpool isolates, T. gondii total cell extracts, cytoskeletal preparations, and hydrophilic and hydrophobic phases of Triton-X-114 extracts) were processed for SDS-PAGE as previously described (Hemphill et al. 1992). Samples corresponding to the same number of parasites were separated by SDSPAGE and transferred to nitrocellulose filters (Towbin et al. 1979). In some experiments, nitrocellulose filters containing bound proteins were treated with $40 \mathrm{~m} M \mathrm{NaIO}_{4}$ in $50 \mathrm{~m} M$ sodium acetate buffer ( $\mathrm{pH} 4.5$; McDonald et al. 1995). Blocking of unspecific binding sites was carried out for $4 \mathrm{~h}$ at $24^{\circ} \mathrm{C}$ in PBS containing $3 \%$ bovine serum albumin (BSA) and 0.3\% Tween-20. The antisera directed against $N$. caninum and and T. gondii were applied at a dilution of $1: 2,000$ in PBS/0.3\% BSA/0.3\% Tween-20 overnight at $4^{\circ} \mathrm{C}$. The filters were then washed three times in PBS/ $0.3 \%$ Tween-20, and the bound antibodies were visualized using peroxidase-conjugated anti-rabbit immunoglobulin antibodies (Promega) according to the instructions provided by the manufacturers.

\section{Affinity purification of specific antibodies against Nc-p43}

Affinity purification of specific antibodies directed against the most immunodominant band from a Triton-X-114 extract was performed essentially as described by Mueller et al. (1992). Briefly, the region corresponding to Nc-p43 was cut out from the nitrocellulose following SDS-PAGE and Western blotting of Triton X-114 extracts. In some cases the strip was treated with $\mathrm{NaIO}_{4}$ as described above. After blocking of unspecific binding sites, the anti$N$. caninum antiserum was applied at a dilution of $1: 20$ in $\mathrm{PBS} / 0.3 \% \mathrm{BSA} / 0.3 \%$ Tween- 20 overnight at $4^{\circ} \mathrm{C}$. After washing of the strip in PBS $/ 0.3 \%$ Tween 20 three times for 10 min each, the bound antibodies were eluted in $900 \mu \mathrm{l}$ of low-pH buffer (50 $\mathrm{m} M$ TRIS, $50 \mathrm{~m} M$ glycine, $0.05 \%$ Tween-20, $\mathrm{pH}$ 2.6) for $5 \mathrm{~min}$ on ice with occasional vortexing. Then the strip was removed and $100 \mu \mathrm{l}$ of $1 M$ TRIS base was immediately added. The eluted antibody fraction was centrifuged $(10,000 \mathrm{~g}, 20 \mathrm{~min})$ to remove small nitrocellulose particles, and BSA was added to a final concentration of $0.1 \%$. Affinity-purified antibodies were aliquoted and stored at $-20^{\circ} \mathrm{C}$. They were used for immunoblotting at a dilution of 1:100.

Both the nitrocellulose strip and the antiserum were usually reused for a second round of affinity purification. After washing of the strip in PBS/0.3\% Tween-20 and subsequent blocking for $4 \mathrm{~h}$ in $\mathrm{PBS} / 3 \% \mathrm{BSA} / 0.3 \%$ Tween-20, the procedure described above 
was repeated. The anti-Nc-p43 antibodies isolated from this second round of purification proved to be suitable for immunoblots at a dilution of 1:50.

\section{Immunofluorescence}

All procedures were carried out at room temperature. Freshly purified $N$. caninum or $T$. gondii tachyzoites suspended in PBS at 10 parasites $/ \mathrm{ml}$ were applied to polylysine-coated $(100 \mu \mathrm{g} / \mathrm{ml})$ glass coverslips. After $10 \mathrm{~min}$ the coverslips were rinsed three times in PBS and were placed in fixation buffer (PBS/3\% paraformaldehyde/0.05\% glutaraldehyde, $\mathrm{pH} 7.2$ ) for $15 \mathrm{~min}$. The coverslips were then rinsed extensively in PBS and were subsequently incubated in blocking solution (PBS/1\% BSA/50 mM glycin) for 30 min. The anti- $N$. caninum and anti-T. gondii antisera were ap plied at dilution of 1:400 and the affinity-purified anti-Nc-p43 antibody was applied at 1:1 in blocking solution for $30 \mathrm{~min}$, followed by three buffer rinses. The second antibody layer (goat antirabbit conjugated to Texas red; Becton Dickinson Immunocytometry Systems) was applied at a 1:100 dilution in blocking buffer. In the case of double-labeling experiments, the third antibody was a monoclonal antibody directed against alpha-tubulin (kindly provided by Tom Seebeck, University of Bern) and a fourth layer comprised fluorescein isothiocyanate (FITC)- conjugated goat an ti-mouse antibody (Cappel). Specimens were then rinsed in PBS (five times for $5 \mathrm{~min}$ ). In some experiments the coverslips were subsequently stained with the DNA-specific dye Hoechst 33258 ( $25 \mu \mathrm{g} / \mathrm{ml}$ in PBS) for $2 \mathrm{~min}$. Finally, the preparations were briefly rinsed in distilled water and were embedded in a mixture of glycerol/gelvatol containing 1,4-diazobicyclo(2,2,2)octane (Merck) as an antifading reagent (Hemphill et al. 1992). Results were obtained by inspection of specimens on a Leitz Laborlux S fluorescence microscope.

\section{Immunogold labeling and transmission electron microscopy}

Purified $N$. caninum and $T$. gondii tachyzoites $\left(5 \times 10^{7} / \mathrm{ml}\right)$ were fixed in suspension employing the same fixation buffer used for immunofluorescence studies. After blocking of unspecific binding sites and three additional washes in blocking buffer, the first antibody layers (diluted as described above) were applied for $60 \mathrm{~min}$ Parasites were then washed in PBS (three times for $5 \mathrm{~min}$ ), and the second layer (goat anti-rabbit antibody conjugated to 10-nm gold particles; Amersham, Zuerich) was applied at a dilution of 1:5 in blocking buffer for $45 \mathrm{~min}$. Gold conjugates were centrifuged at $4,800 \mathrm{~g}$ for $10 \mathrm{~min}$ to remove possible aggregates (Hemphill et al. 1991). After three washes in PBS, the labeled parasites were fixed in $2 \%$ glutaraldehyde diluted in $100 \mathrm{~m} M$ sodium phosphate buffer $\left(\mathrm{pH} 7.2\right.$ ) for $4 \mathrm{~h}$ at $4^{\circ} \mathrm{C}$. The parasites were then washed in phosphate buffer, postfixed in $2 \% \mathrm{OsO}_{4}$, dehydrated in a graded series of ethanol, and embedded in Epon 812 (Fluka Chemicals, Switzerland) as previously described (Hemphill et al. 1996). The preparations were finally polymerized at $65^{\circ} \mathrm{C}$ for $24-48 \mathrm{~h}$. Thin sections were cut with a diamond knife using a Reichert and Jung ultramicrotome, and grids were stained with lead citrate and uranyl acetate (Smith and Croft 1991).

\section{Results}

Characterization of anti-Neospora caninum and anti-Toxoplasma gondii antisera

Polyclonal antisera were raised in rabbits immunized with purified, intact $N$. caninum ( $\mathrm{Nc}-1$-isolate) and $T$. gondii tachyzoites, respectively. These antisera were first characterized by SDS-PAGE and immunoblotting with regard to their reactivity with cell extracts derived from

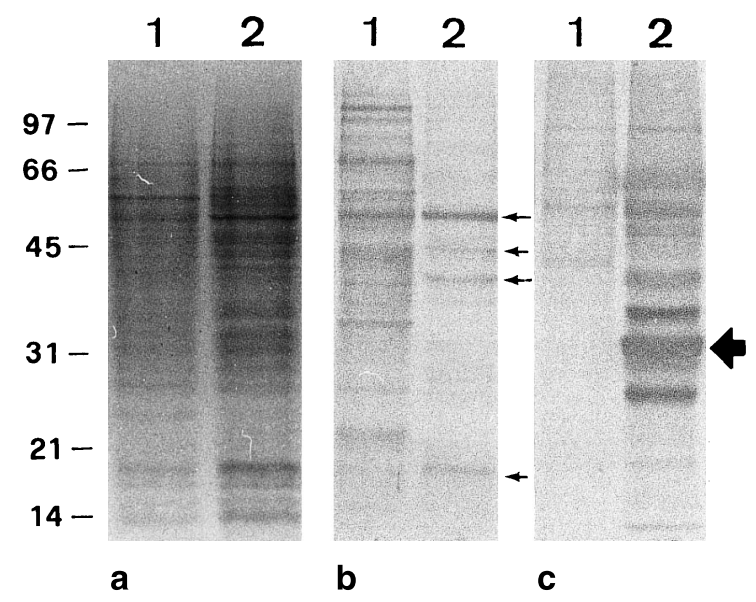

Fig. 1a-c Coomassie-stained SDS-PAGE of total cell extracts (a) and corresponding immunoblots labeled with anti-Neospora caninum (b) and anti-Toxoplasma gondii (c) antisera (Lane $1 \mathrm{~N}$. caninum tachyzoites, lane $2 \mathrm{~T}$. gondii tachyzoites). Note the relative specificity of the two antisera with respect to the species they were raised against. The small arrows indicate cross-reacting bands in T. gondii extracts, and the large arrow shows the position of P30, the major $T$. gondii surface antigen

these two parasites. Figure 1 illustrates the differences found in the reactivities of the two antisera. The anti- $N$. caninum antiserum recognized a high number of proteins in $N$. caninum ( $\mathrm{Nc}-1$ ) extracts, but the affinity for epitopes in $T$. gondii cell lysates was mainly restricted to distinct bands of 48, 43, and $40 \mathrm{kDa}$ (Fig. 1B). The anti$T$. gondii antiserum, however, reacted very intensely with many bands in $T$. gondii extracts, one of which presumably was P30, the major surface antigen, but labeling of bands in $N$. caninum extracts was almost absent (see Fig. 1C).

To find out whether these two antisera would bind to epitopes present on the surface of tachyzoites, parasites were fixed in a mixture of 3\% paraformaldehyde $/ 0.05 \%$ glutaraldehyde in PBS (conditions that are recommended for preserving the integrity of the cell surface) and immunofluorescence staining was performed. Immunofluorescence labeling demonstrated a clear specificity of these two antisera toward the species against which they were raised, at least with respect to cell-surface-exposed epitopes (Fig. 2a-d). In addition, prefixed $N$. caninum (Nc-1) tachyzoites were immunogold-labeled using the anti- $N$. caninum antiserum and were subsequently embedded in Epon 812, and thin sections were inspected by TEM. Dense labeling was seen distributed uniformly all over the parasite cell surface (Fig. 2e). Gold particles were absent in control experiments using preimmune serum as the first antibody layer, and immunogold labeling of $T$. gondii tachyzoites with anti- $N$. caninum antiserum also failed to result in binding of gold particles to the Toxoplasma cell surface (data not shown). These initial experiments demonstrated that the antiserum directed against $N$. caninum ( $\mathrm{Nc}-1$ ) tachyzoites represents a valuable tool for the further identification of specific cell-surface components of this parasite. 
Fig. 2a-e Cell-surface labeling of $N$. caninum (a, d) and $T$. gondii $(\mathbf{b}, \mathbf{c})$ tachyzoites as obtained using antisera directed against these two parasites. a, b Tachyzoites labeled with anti- $N$. caninum antiserum. c, d Tachyzoites labeled with anti- $T$. gondii antiserum. Note the absence of fluorescent staining in $\mathbf{b}$ and $\mathbf{d}$. e Immunogold surface labeling of $N$. caninum tachyzoites as obtained using anti- $N$. caninum antiserum. Note the uniform, dense labeling of the tachyzoite surface
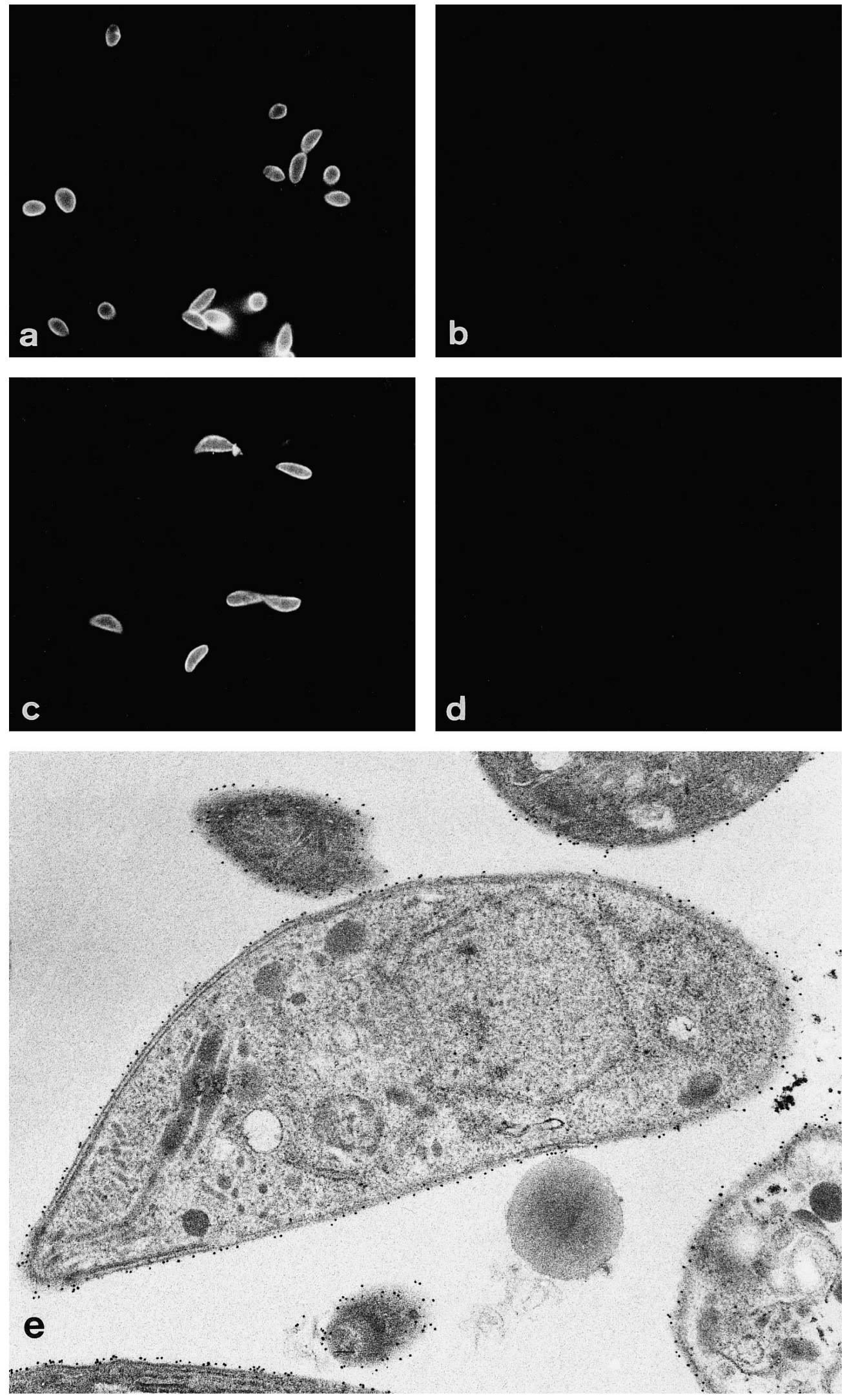


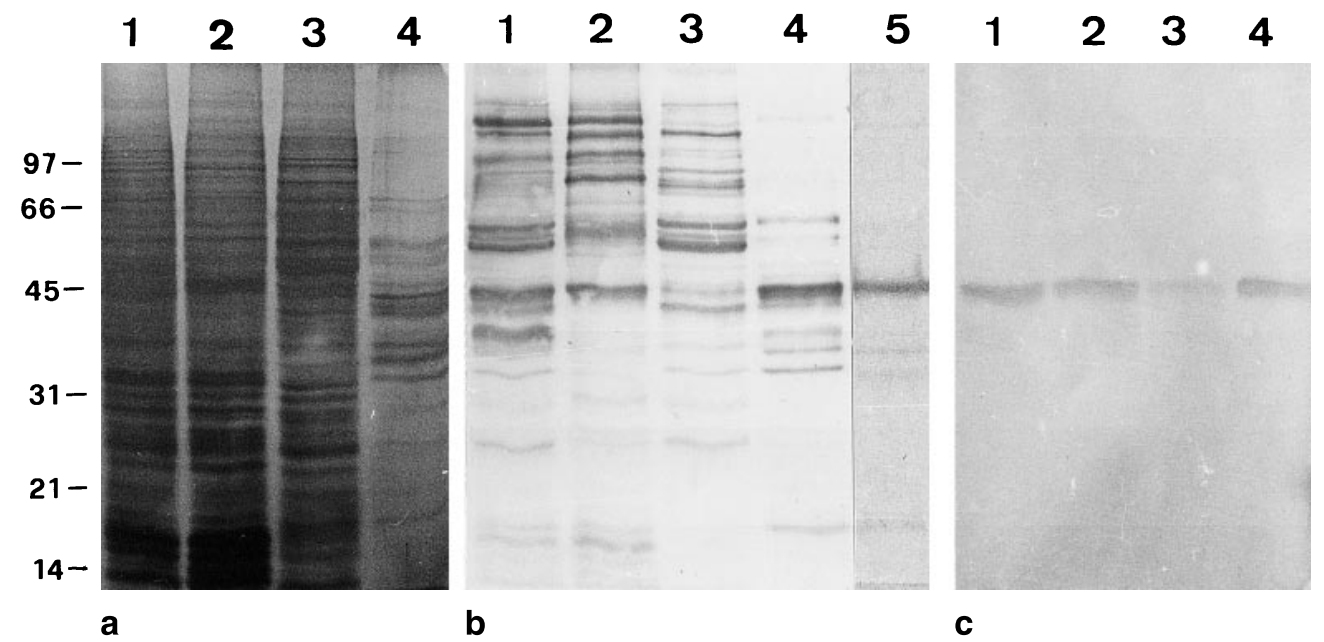

Fig. 3a-c Subcellular fractionation of N. caninum tachyzoites. A Silver-stained SDS-PAGE. Amounts corresponding to the same number of tachyzoites were loaded ( 1 Total cell extract, 2 Triton $\mathrm{X}$-114-insoluble fraction, 3 Triton X-114-soluble hydrophilic phase, 4 Triton X-114-soluble apolar phase). b Corresponding immunoblots labeled with anti- $N$. caninum antiserum (Lanes 1-4 As defined in a, lane 5 immunoblot of the Triton X-114-soluble apolar fraction after chemical deglycosylation with sodium periodate). C Immunoblots corresponding to those shown in a as obtained using affinity-purified anti-Nc-p43 antibody. Note the absence of Nc-p43 in the hydrophilic Triton-X-114 fraction

\section{Subcellular fractionation of $N$. caninum tachyzoites}

We applied a subcellular fractionation approach employing extraction and phase separation in the nonionic detergent Triton X-114. Phase separation at elevated temperature $\left(30^{\circ} \mathrm{C}\right)$ separated hydrophilic Triton $\mathrm{X}-114$ soluble proteins from the hydrophobic components constituting potential integral membrane proteins. The different steps of the subcellular fractionation of $N$. caninum tachyzoites of the Nc-1 isolate are summarized in Fig. 3. Fig. 3B demonstrates in immunoblots of SDS-PAGE-separated extracts the reactivity of the whole-cell-lysate, the cytoskeletal fraction, and the hydrophilic and hydrophobic phases of Triton X-114 extracts with the anti- $N$. caninum antiserum. The most immunodominant protein in the apolar phase of Triton X-114 extracts migrated at a molecular weight of approximately $43 \mathrm{kDa}$ (Fig. 3B, lane 4). To determine whether the epitopes recognized by the polyclonal anti- $N$. caninum antiserum in the apolar Triton $\mathrm{X}-114$ fraction were of proteinous or carbohydrate nature, deglycosylation of nitrocellulose-bound proteins was achieved by sodium periodate treatment. Whereas chemical deglycosylation profoundly diminished antibody-binding activity to several nitrocellulose-bound polypeptides, binding of antibodies to the $43-\mathrm{kDa}$ protein remained largely unaffected (Fig. 3B, lane 5). This suggested that the epitopes, or at least a large portion of them, on this most immunodominant molecule were not constituted of carbohydrates. This protein was subsequently named Nc-p43.
Nc-p43 was also clearly visible on nitrocellulose filters that had been stained with Ponceau red after transfer of SDS-PAGE-separated proteins. Affinity purification of anti-Neospora antiserum on this particular band was perfomed to obtain an immunoglobulin fraction that was specific for Nc-p43. The specificity of these affinity-purified antibodies with respect to other proteins in all subcellular fractions of $N$. caninum ( $\mathrm{Nc}-1)$ is demonstrated in Fig. 3C.

Nc-p43 is a cell-surface-associated protein in $N$. caninum but not in $T$. gondii

Affinity-purified anti-Nc-p43 antibodies were used to demonstrate the location of this molecule on $N$. caninum tachyzoites of the Nc-1 isolate. Double-immunofluorescence experiments were performed. Purified tachyzoites were fixed as described above and were incubated with affinity-purified anti-Nc-p43 antibodies and a second antibody conjugated to Texas red. Staining of the N. caninum tachyzoite surface was evident (Fig. 4a). Identical results were obtained when tachyzoites of the $N$. caninum Liverpool isolate were immunolabeled with affinitypurified anti-Nc-p43 antibodies (data not shown). For verification that the fixation procedure employed really did reflect labeling of the cell surface and not of internal proteins, the same preparations were subsequently incubated with a monoclonal anti-tubulin antibody and a goat anti-mouse antibody conjugated to FITC. Only those cells that remained unlabeled with the monoclonal antibody reflected true cell-surface staining (Fig. 4b). In addition, $T$. gondii tachyzoites were fixed identically and were processed for fluorescence surface staining as described above (Fig. 4d, e). The complete absence of immunolabel from $T$. gondii tachyzoites suggested that Ncp43 was a Neospora-specific molecule. Preembedding immunogold surface labeling of $N$. caninum tachyzoites using anti-Nc-p43 antibodies was performed to show conclusively the presence of this protein on the tachyzoite surface. Gold particles were distributed along the entire surface of the tachyzoites (Fig. 4e), demonstrating 
Fig. 4a-f Cell-surface labeling of $N$. caninum $(\mathbf{a}-\mathbf{c}, \mathbf{f})$ and $T$. gondii $(\mathbf{d}, \mathbf{e})$ tachyzoites with affinity-purified anti-Nc-p43 antibody. $N$. caninum tachyzoites were surface-labeled with anti-Nc-p43 (a) and a monoclonal anti-tubulin antibody (b) to demonstrate those tachyzoites that were no longer intact (arrowheads). The nuclei of tachyzoites were labeled with Hoechst 33258 (c) to show that all parasites express the cell-surface protein Nc-p43. d T. gondii tachyzoites surface-labeled with affinity-purified anti-Ncp43 antibody. e The same $T$. gondii stained with Hoechst 33258. f $N$. caninum tachyzoite immunogold-labeled with affinity-purified anti-Nc-p43 antibody and goat anti-rabbit antibody conjugated to 10 -nm gold particles. Note the uniform distribution of gold particles on the tachyzoite surface
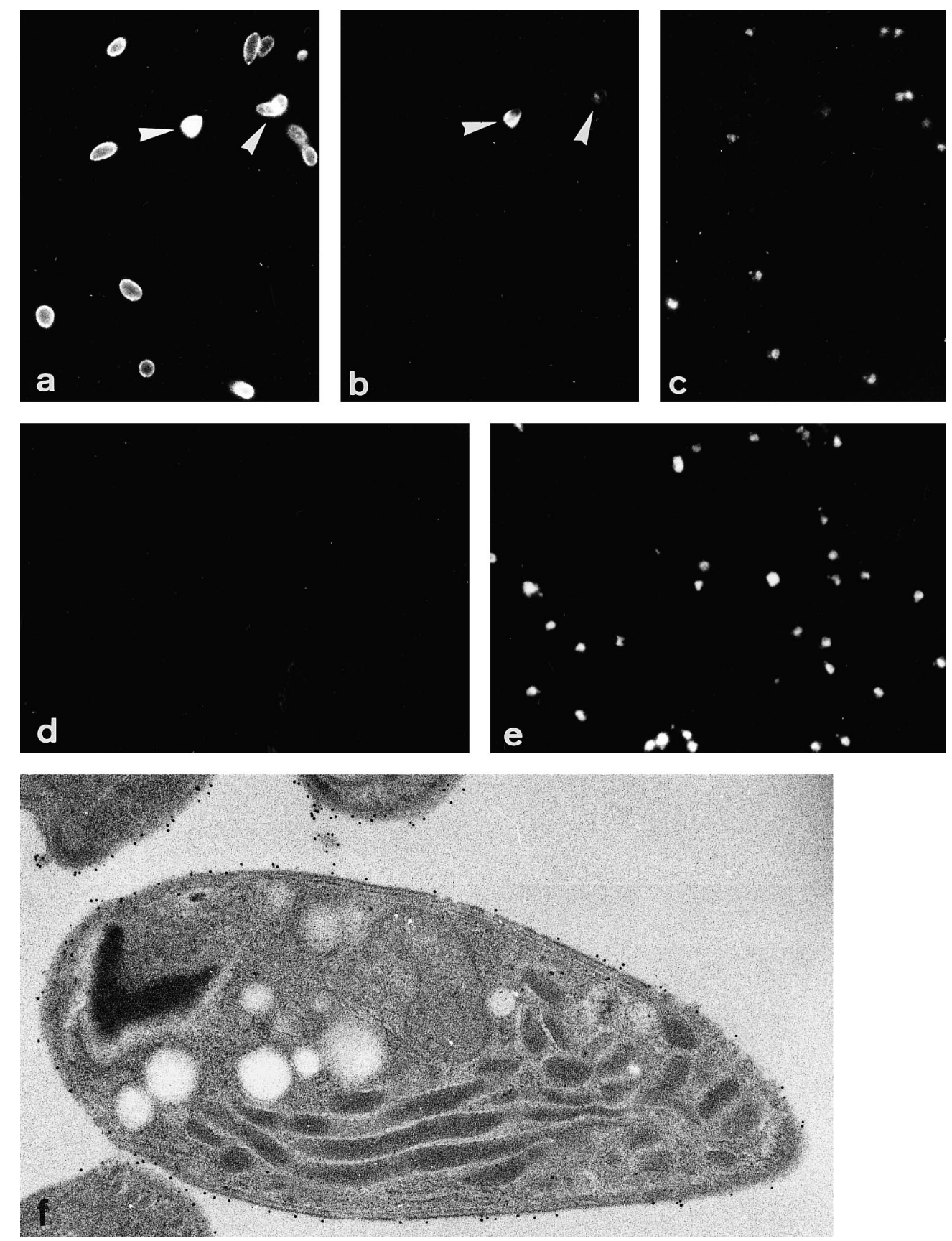

with affinity-purified anti-Ncp43 antibody, demonstrating the presence of this molecule in an American isolate ( $\mathrm{Nc}-1$, lane 1) and a European isolate (Liverpool, lane 2). Note that Nc-p43 is absent from the $T$. gondii RH strain (lane 3)

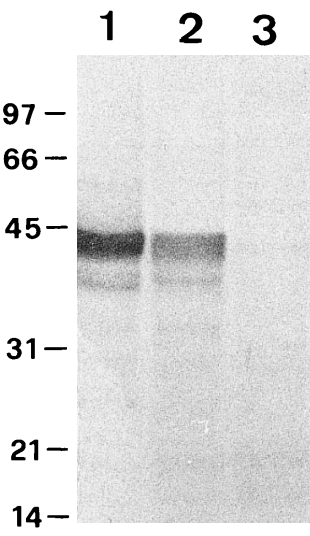

that Nc-p43 was indeed a major cell-surface protein. The presence of $\mathrm{Nc}-\mathrm{p} 43$ in cell lysates of $N$. caninum $(\mathrm{Nc}-1$ and Liverpool isolates) and the absence of an immunologically related protein in $T$. gondii was further confirmed by immunoblotting employing the affinity-purified anti-Nc-p43 antibody (Fig. 5).

\section{Discussion}

Specific receptor-ligand interactions, usually mediated by cell-surface-associated molecules, are a prerequisite for microbial colonialization and pathogenesis. This is documented by the observation that surface molecules of 
intracellular parasites play important roles with respect to the process of adhesion to and invasion of host cells, the intracellular development of these pathogens, and the presentation of antigens as these parasites are internalized by antigen-presenting cells such as macrophages. Thus, parasite molecules that are accessible to host immune or nonimmune components carry out key functions during the host-parasite interplay. To our knowledge, only very limited information is available on host-parasite interactions in neosporosis (Hemphill et al. 1996), and we therefore undertook a first step in this direction by investigating the composition of the cell surface of Neospora caninum tachyzoites.

This paper reports on the identification of a cell-surface-associated protein of $43 \mathrm{kDa}$ in an American isolate (Nc-1; Dubey et al. 1988) and a European (Liverpool; Barber et al. 1993) isolate of $N$. caninum. An immunologically related protein is apparently not present in the Toxoplasma gondii RH strain. The Neospora surface protein Nc-p43 was identified using a polyclonal antiserum generated in rabbits by inoculation of live $N$. caninum tachyzoites into these animals (Hemphill et al. 1996). The original plan focused on the affinity purification of this antiserum on distinct bands of SDS-PAGE-separated total cell extracts and the use of affinity-purified antibodies for localization studies so as to determine the distribution of the corresponding epitopes on $N$. caninum tachyzoites (Mueller and Felleisen 1995). However, our antiserum generated a very complex banding pattern on immunoblots of $N$. caninum cell extracts (see Fig. 1). This confirmed the results previously obtained by other authors (Barta and Dubey 1992; Bjerkås et al. 1994; Bjoerkman et al. 1994), and it was therefore necessary to undertake subcellular fractionation so as to achieve antibody labeling of distinct, immunopositive bands (see Fig. 3).

Triton-X-114 extraction and subsequent phase separation has been employed by other investigators for the isolation of parasite cell-surface membrane-associated proteins (Bouvier et al. 1985). By immunoblot analysis of the Triton X-114 detergent-phase extracts of $N$. caninum with the polyclonal antiserum the number of immunoreactive proteins was significantly reduced, exhibiting a clearly discernible banding pattern (see Fig. 3). The most immunodominant band had a molecular weight of approximately $43 \mathrm{kDa}$. Antibodies affinity-purified on the 43-kDa band reacted strongly with cell-surface epitopes of $N$. caninum but did not react with those of $T$. gondii (see Fig. 4). This suggested the potential of this protein to represent a convenient tool for the discrimination of these two species by serological means. Respective investigations are currently being carried out in our laboratory.

Immunodominant proteins of $N$. caninum have also previously been identified by other groups working in the field. The most immunodominant antigens of $N$. caninum recognized by hyperimmunsera directed against this parasite have been described by Barta and Dubey (1992) as four antigens with approximate molecular weights of $16 / 17,29,37$, and $46 \mathrm{kDa}$, respectively. Bjerkås et al. (1994) reported that the dominating $N$. caninum antigens recognized by immune sera from various species had apparent molecular weights of 17, 29, 30 , and $37 \mathrm{kDa}$. However, immunoelectron microscopy studies employing the respective sera have shown that these antigens were located not in the surface membrane but in rhoptries, dense granules, micronemes, the tubular network, and the membrane of the parasitophorous vacuole (Barta and Dubey 1992; Bjerkås et al. 1994). Bjoerkman et al. (1994) characterized antigens that are currently used in an enzyme-linked immunosorbent assay (ELISA) for diagnosis of Neospora infections. This group of antigens comprised four proteins of 52-61 kDa, and three proteins of 31-36 kDa. As these antigens were isolated by ISCOM preparations and since ISCOM are formed by hydrophobic interactions (Araujo 1994), the isolation procedure selected for amphipatic molecules such as membrane proteins (Hoeglund et al. 1989), a membrane-associated location was suggested for these antigens as well.

Chemical deglycosylation of nitrocellulose-bound proteins from SDS-PAGE-separated Triton X-114 extracts significantly altered the staining intensity of several bands when these were probed with the polyclonal anti- $N$. caninum antiserum, but the reactivity of antibodies directed against the 43-kDa band remained largely unaffected (see Fig. 3). Our previous investigations (Hemphill et al. 1996) have shed some light on the role of carbohydrate residues on the $N$. caninum cell surface in relation to adhesion to and invasion of host cells. Sodium periodate treatment of $N$. caninum tachyzoites, which would remove potential carbohydrate residues from the parasite cell surface, had no effect on the capacity of these parasites to adhere to and invade bovine endothelial host cells. In addition, preincubation of parasites with tunicamycin and treatment of parasites with several lectins were ineffective in achieving an inhibition of the adhesion or invasion process (Hemphill et al. 1996). In contrast, protease treatment of tachyzoites suggested that removal of proteins or protein fragments from the parasite surface altered the molecules responsible for mediating the interaction of $N$. caninum with the monolayer. Thus, carbohydrate residues were probably not important during the initial phases of the invasion process, but it is likely that the interaction between parasites and host cells involved specific proteinous molecules that would act as ligands, mediating host-cell recognition and invasion (Hemphill et al. 1996).

Nc-p43 could very likely be one of these proteins that participate in the adhesion and/or invasion process of $N$. caninum tachyzoites. However, this question needs further investigation employing specific antibodies directed against Nc-p43 with respect to their capacity to block the entry of the parasite into the intracellular compartment of its host.

Acknowledgements The authors want to acknowledge the encouraging support of Hannes Kaufmann (Bundesamt für Veterinärwesen) during the initial stages of this study and to express their gratitude to Giovanni Rossi (Institute of Veterinary Pathology, University of Berne) for letting us perform ultramicrotomy in 
his laboratory and Toni Wyler (Insitute for Zoology, University of Berne) for his help in electron microscopy. Many thanks to Norbert Mueller and Richard Felleisen for stimulating discussions and critical comments on the manuscript, to Olivier Flechtner for his valuable help in cell culturing, and to Vreni Zimmermann for excellent technical assistance. The $N$. caninum isolate $\mathrm{Nc}-1$ was a kind gift from J. P. Dubey (U.S. Department of Agriculture, Beltsville, Md.) and Joakim Holmdahl (Swedish University of Agricultural Sciences, Uppsala). N. caninum Liverpool was kindly provided by Alexander Trees (Liverpool School of Tropical Medicine). The monoclonal antibody directed against tubulin was a gift from Tom Seebeck (Institute for General Microbiology, University of Berne), and crucial support during this study was given by Banu Yuerueker. This project was funded by the Bundesamt für Veterinärwesen (project 002.4.3.931), Switzerland.

\section{References}

Araujo FG (1994) Immunization against Toxoplasma gondii. Parasitol Today 9: 358-360

Barber JA, Trees AJ, Owen M (1993) Isolation of Neospora caninum from a British dog. Vet Rec 133: 531-532

Barr BC, Rowe JD, Sverlov KW, Bon Durant RH, Ardans A, Oliver MN, Conrad PA (1994) Experimental reproduction of bovine fetal Neospora infection and death with a Neospora isolate. J Vet Diagn Invest 6: 207-215

Barta JR, Dubey JP (1992) Characterization of anti-Neospora caninum hyperimmune rabbit serum by Western blot analysis and immunoelectron microscopy. Parasitol Res 78: 689-694

Bjerkås I, Presthus J (1988) Immuno-histochemical and ultrastructural characteristics of a cyst-forming sporozoon associated with encephalomyelitis and myositis in dogs. Acta Pathol Microbiol Immunol Scand [B] 96: 445-454

Bjerkås I, Jenkins MC, Dubey JP (1994) Identification and characterization of Neospora caninum tachyzoite antigens useful for diagnosis of neosporosis. Clin Diagn Lab Immunol 1: 214-221

Bjoerkman C, Lunden A, Holmdahl J, Barber J, Trees AJ, Uggla A (1994) Neospora caninum in dogs: detection of antibodies by ELISA using an iscom antigen. Parasite Immunol 16: 643-648

Bonhomme A, Pingret L, Pinon JM (1992) Review: Toxoplasma gondii cellular invasion. Parassitologia 34: 31-43

Bouvier J, Etges R, Bordier C (1985) Identification and purification of membrane and soluble forms of the major surface protein of Leishmania promastigotes. J Biol Chem 260: 15504-15509

Brindley PJ,Gazzinelli RT, Denkers EY, Davis SW, Dubey JP, Belfort R, Martins M-C, Silveira C, Jamra L, Waters AP, Sher A (1993) Differentiation of Toxoplasma gondii from closely related coccidia by riboprint analysis and a surface antigen gene polymerase chain reaction. Am J Trop Med Hyg 48: 447-456

Burg JL, Grover CM, Pouletty P, Boothroyd JC (1989) Direct and sensitive detection of a pathogenic protozoan, Toxoplasma gondii, by polymerase chain reaction J Clin Microbiol 27: $1787-1792$

Dubey JP (1992) A review of Neospora caninum and Neosporalike infections in animals. J Protozool Res 2: 40-54

Dubey JP, Lindsay DS (1993) Neosporosis. Parasitol Today 9: $452-458$

Dubey JP, Carpenter JL, Speer A, Topper MJ, Uggla A (1988) Newly recognized fatal protozoan disease of dogs. J Am Vet Med Assoc 198: 1269-1285

Ellis J, Luton K, Baverstock PR, Brindley PJ, Nimmo KA, Johnson AM (1994) The phylogeny of Neospora caninum. Mol Biochem Parasitol 64: 303-311
Hemphill A, Seebeck T, Lawson D (1991) The Trypanosoma brucei cytoskeleton: ultrastructure and localization of microtubule-associated and spectrin-like proteins using quick-freeze, deep-etch, immunogold electron microscopy. J Struct Biol 107: $211-110$

Hemphill A, Affolter M, Seebeck T (1992) A novel microtubule binding motif identified in a high molecular weight microtubule-associated protein from Trypanosoma brucei. J Cell Biol 117: 95-103

Hemphill A, Gottstein B, Kaufmann H (1996) Adhesion and invasion of bovine endothelial cells by Neospora caninum. Parasitology (in press)

Hoeglund S, Dalsgaard K, Loevgren K (1989) ISCOMS and immunostimulation with viral antigens. In: Harris JR (ed) Subcellular biochemistry. Plenum, New York, p 39

Holmdahl OJM, Mattson JG, Uggla A, Johansson K (1994) The phylogeny of Neospora caninum and Toxoplasma gondii based on ribosomal RNA sequences. Fed Eur Microbiol Soc Microbiol Lett 119: 187-192

Joiner KA, Dubremetz JF (1993) Toxoplasma gondii: a protozoan for the nineties. Infect Immun 61: 1169-1172

Kasper LH, Mineo JR (1994) Attachment and invasion of host cells by Toxoplasma gondii. Parasitol Today 10: 184-188

Lindsay PS, Dubey JP (1989) In vitro development of Neospora caninum (Protozoa: Apicomplexa) from dogs. J Parasitol 75: $163-165$

Lindsay PS, Speer CA, Toivio-Kinnucan MA, Dubey JP, Blagburn BL (1993) Use of infected cultured cells to compare ultrastructural features of Neospora caninum from dogs and Toxoplasma gondii. Am J Vet Res 54: 103-106

Marsh AE, Barr BC, Sverlow K, Ho M, Dubey JP, Conrad PA (1995) Sequence analysis and comparison of ribosomal DNA from bovine Neospora to similar coccidial parasites. J Parasitol 81: 530-535

McDonald V, McCrossan MV, Petry F (1995) Localization of parasite antigens in Cryptosporidium parvum-infected epithelia cells using monoclonal antibodies. Parasitology 110: 259-268

Mueller N, Felleisen R (1995) Bacterial expression systems as tools for the production of immunodiagnostic parasite antigens. Parasitol today (in press)

Mueller N, Hemphill A, Imboden M, Duvallet G, Dwinger RH, Seebeck T (1992) Identification and characterization of two repetitive non-variable antigens from African trypanosomes which are recognized early during infection. Parasitology 104: $111-120$

Sabin A (1941) Toxoplasmic encephalitis in children. JAMA 116 : $801-814$

Seefeldt SL, Kirkbride CA, Dubey JP (1989) Comparison of enzyme-linked immunosorbent assay, direct fluorescent antibody test, and direct agglutination test for detecting Toxoplasma gondii antibodies in naturally aborted ovine fetuses. J Vet Diagn Invest 1: 124-127

Smith M, Croft SL (1991) Embedding and thin section preparation. In: Rickwood D, Harris BD (eds) Electron microscopy in biology. A practical approach. IRL, Oxford, pp 17-37

Towbin H, Staehelin T, Gordon J (1979) Electrophoretic transfer of proteins from polyacrylamide gels to nitrocellulose sheets: procedure and some applications. Proc Natl Acad Sci USA 76: 4350-4354

Trees AJ, Tennant BJ, Kelly DF (1991) Paresis in dogs and Neospora caninum. Vet Rec 129: 456

Werk R (1985) How does Toxoplasma gondii enter host cells? Rev Infect Dis 7: 449-457

Wessel D, Fluegge UI (1984) A method for the quantitative recovery of protein in dilute solution in the presence of detergent. Anal Biochem 138: 141-143 